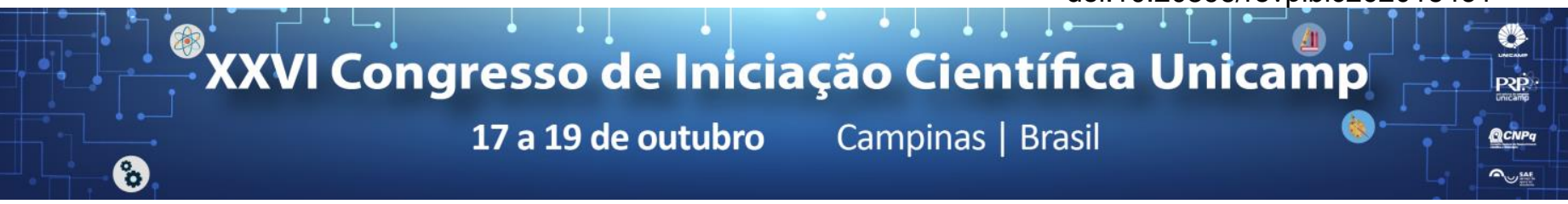

\title{
Compositional Analysis of Semolina with Added Fibers by Near Infrared Spectroscopy (NIR).
}

\section{Fernanda Lie Morimitsu¹, Amanda Teixeira Badaró1, Amanda Rios Ferreira², Maria Teresa Pedrosa Silva Clerici² Douglas Fernandes Barbin'1}

\section{Abstract}

Fiber addition to semolina is important to promote better health, since fibers help to prevent chronical diseases such as obesity and diabetes. Since traditional methods for fiber determination are slow and demand sample preparation, the development of less invasive techniques is necessary. Therefore, near infrared spectroscopy (NIR) was used as a fast and non-destructive method to identify fibers added to semolina.

Key words: NIR, Fiber, Semolina

\section{Introduction}

Fiber addition in semolina is interesting because of its importance for human health, regarding cholesterol levels, blood glucose and insulin and preventing heart diseases and diabetes type $2^{1}$. Traditional analysis of flour components is time consuming ${ }^{2}$. The main objective of this project was to apply near infrared spectroscopy (NIRS) to identify fibers added to semolina.

\section{Results and Discussion}

Spectral information in the NIR range of three types of semolinas and 10 different fibers were obtained. Mixtures were prepared with $3,5 \%$ and $7 \%$ of fiber added to semolina. Principal Component Analysis (PCA) with SNV and $1^{\text {st }}$ derivative provided the best separation between different samples of semolina and fiber. The graphics below show the separation of fibers and three semolinas.

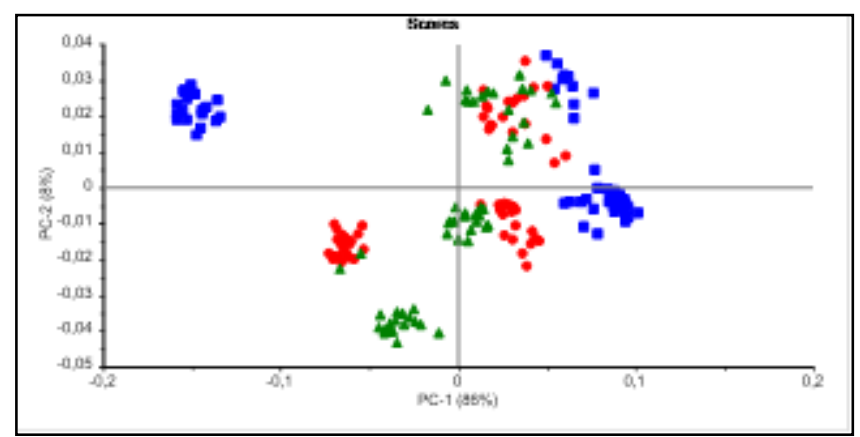

Image 1. Fiber 1 PCA scores. Blue: semolina; Red: semolina with $3.5 \%$ of fiber; Green: semolina with $7 \%$ of fiber.

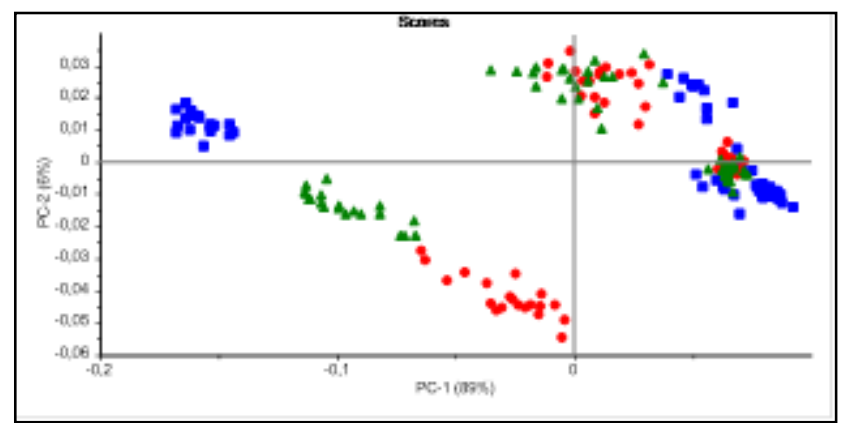

Image 2. Fiber 2 PCA scores, Blue: semolina; Red: semolina with $3.5 \%$ of fiber; Green: semolina with $7 \%$ of fiber.

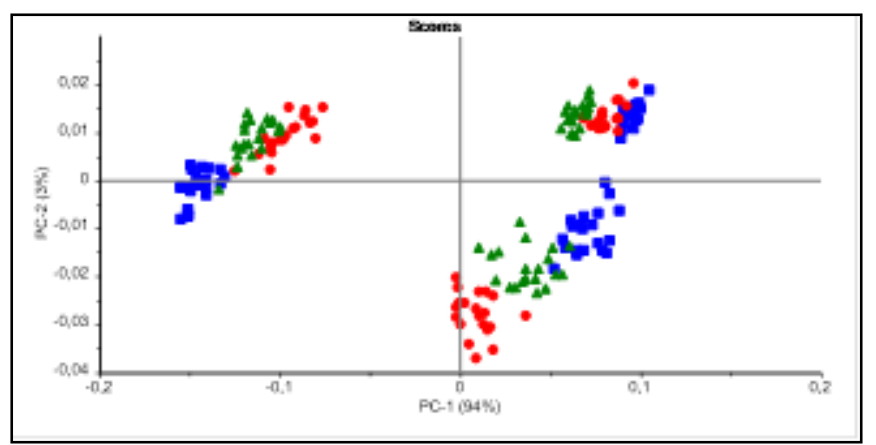

Image 3. Fiber 3 PCA scores, Blue: semolina; Red: semolina with $3.5 \%$ of fiber; Green: semolina with $7 \%$ of fiber

PCA scores (Images 1, 2 and 3) have shown differences among pure semolina. Fiber 1 has shown very good separation, not only between semolina types, but also for different fiber types. These contrasts are probably due to the difference of physical properties between fibers and semolinas, which makes the mixture less homogeneous.

\section{Conclusions}

It was possible to identify different types of fiber added to semolina, but they mixed differently. Further studies are necessary due to the behavior of fibers in the mixed samples.

\section{Acknowledgement}

The authors are thankful to the Cereal, Roots and Tubers Laboratory (Labcer) from FEA/Unicamp, for providing fiber samples. They are also thankful to FAPESP (process number 2015/24351-2) and to SAE/Unicamp for the financial support.

Affiliations: 'University of Campinas (Unicamp), Department of Food Engineering (DEA), School of Food Engineering (FEA), Campinas, São Paulo, Brazil.

2University of Campinas (Unicamp), Department of Food Technology (DTA), School of Food Engineering (FEA), Campinas, São Paulo, Brazil.

11 Marlett, J. A.; Mcburney, M. I.; Slavin, J. L.; Hopk, J. Position of the American Dietetic Assiciation: health implication of dietary fiber. Journal of the American Dietetic Assiciation, v.102, n. 7, p. 993-1000, 2002.

${ }^{2}$ Huang, H., Yu, H., Xu, H. \& Ying, Y. (2008). Near Infrared Spectroscopy for on/in-line Monitoring of Quality in Foods and Beverages: a Review. Journal of Food Engineering, v. 87, p. 303-313. 